\title{
Diagnostic Study of Venereal Disease Research Lab (VDRL), Malaria Parasite (MP) and Blood Grouping in Human Blood Donors
}

\author{
Sumaya Amin ${ }^{1}$, Anwar Ali ${ }^{2}$, Imran Khan ${ }^{3}$, Bushra Bibi ${ }^{1}$, Kausar Saeed ${ }^{4}$ and Muzafar Shah ${ }^{1 *}$ \\ ${ }^{1}$ Centre for Animal Sciences \& Fisheries, University of Swat, Pakistan \\ ${ }^{2}$ Department of Biochemistry, Saidu Medical College, Saidu Sharif Swat, Pakistan \\ ${ }^{3}$ Department of Physiology, Saidu Medical College, Saidu Sharif Swat, Pakistan \\ ${ }^{4}$ Department of Zoology, University of Buner, Pakistan \\ *Corresponding author: Muzafar Shah, Centre for Animal Sciences \& Fisheries, University of Swat, Pakistan
}

\section{ARTICLE INFO}

Received: 幽 April 01, 2021

Published: 蔧 April 20, 2021

Citation: Sumaya Amin, Bushra Bibi, Anwar Ali, Imran Khan, Muzafar Shah, et al., Diagnostic study of Venereal Disease Research Lab (VDRL), Malaria Parasite (MP) and Blood Grouping in Human Blood Donors. Biomed J Sci \& Tech Res 35(2)2021. BJSTR. MS.ID.005665.

Keywords: VDRL; Syphilis; Blood Donors; MP; Blood Grouping; Prevalence; RDTs; Swat

\begin{abstract}
Our current study was conducted on the Prevalence of VDRL, MP and Blood grouping of Human blood donors in University of Swat. The aim and objective of our current study is to determine the prevalence of VDRL and MP and distribution of blood groups among males, district Swat. For this purpose, A totals of 65 blood donors' were screened for the above disease, out of which, 24 collected from Al-Fajar Foundation, Gulkada and 41 from Frontier Foundation, Mingora. The results shows that the donors were non-reactive for VDRL and MP whereas the ABO blood groups distribution among males, were $32.30 \%$, was group A, $35.30 \%$ was group $B, 10.7 \% \mathrm{AB}$ and $21.50 \%$ were 0 . The prevalence of $A+$ blood group were $32.3 \%$, B+ blood group were $32.3 \%$, $0+$ blood group were $21.5 \%$, $\mathrm{AB}+$ blood group were $9.23 \%, \mathrm{AB}$ - blood group were $1.53 \%$ and the 0 - and $\mathrm{A}$ - blood groups were not found among male blood donors. This study concludes that, there are no reactive or positive cases of VDRL and MP among male blood donors, so that's why there is no prevalence of VDRL and MP among male blood donors of the District Swat, and the $\mathrm{A}+(32.3 \%)$ and $\mathrm{B}+(32.3 \%)$ blood groups are very common in the swat and the blood group 0 - and A- are very rare.
\end{abstract}

Abbreviations: VDRL: Venereal Disease Research Laboratory; FTA-ABS: Fluorescent Treponemal Antibody Absorption; MICT: Mother-to-Child Transmission; ANC: Antenatal Care; TTIs: Transfusion Transmitted Infections; RBC: Red Blood Cells

\section{Introduction}

Venereal Disease Research Laboratory (VDRL) test is a nontreponemal test, used for the screening of syphilis. VDRL test still the most used test throughout the world. And still remains unchallenged. CSF VDRL test is very specific for neurosyphilis [1]. There are three basic methods used for syphilis screening such as dark field microscopy, notreponemal and treponemal to identify spirochete. The more sensitive nontreponemal tests are VDRL and RPR use for early screening; while specific treponemal test is Fluorescent Treponemal Antibody Absorption (FTA-ABS) use to confirm diagnosis [2]. Syphilis infection caused by Treponema pallidum belongs to spirochete group of bacteria; also assist the transmission of HIV [3,4]. According to World Health Organization about 12 million endure the syphilis throughout the world in every year. The oral and genital mucus are more sensitive to Treponema pallidum bacteria [5]. Syphilis infection can be transfer from mother to child [6]. Mother-to-child transmission (MICT) of syphilis during pregnancy can cause a serious fetal outcomes in the second or third trimester such as early fetal death, stillbirth, neonatal death, preterm birth, low birth weight and congenital infections in infants [7]. Syphilis is the second most common infection causing of stillbirth worldwide [8]. Preventing MTCT of syphilis through expanded early testing in antenatal care (ANC) and immediate treatment with a single injection of benzathin penicillin [9], is highly cost-effective $[10,11]$. 
Humanblood and blood products are used for the prevention and treatment of life threatening-disease and also reduced transfusion transmitted infections (TTIs) such as syphilis infections, HIV, HBV, and HCV [12]. The transfusion of unscreened or screened blood and blood products are the major source of TTIs in developing countries like India [13]. It has been found that genetically determined ABO blood group antigen which is present in blood may block binding of possible TTIs causative organism to polysaccharides on cell but non-secretor are lacking in their antigen and are at risk to variety of infections TTIs [14]. Blood group means the entire blood group system contain red blood cells (RBC) antigens that are controlled by specific genes. Karl Landsteiner has been credited for the discovery of ABO blood group system in 1900 [15]. Discovery of ABO blood group system extend the way for discoveries in the field of immune haematology, blood transfusion among humans [16]. The ABO blood group is divided into four blood types (A, B, AB, and 0 ) on the basis of presence or absence of $A$ and $B$ surface antigens. $A B O$ blood group is major because of the certainty that A and B are strongly antigenic and anti A and anti B is naturally develop antibodies present in the serum of individuals require the analogous antigen. These antibodies have ability to produce intravascular hemolytic in case of incompatible transfusion [17]. The Rh (Rhesus) system is the second most important blood group system in human blood transfusion with presently 50 antigens.

The mostimportant antigen is the $\mathrm{D}$ antigen, because it produces immune system response of the five $\mathrm{Rh}$ antigens. D-negative persons have no any anti-D IgG or IgM antibodies, because anti-D antibodies are not normally produce by the hypersensitivity against the environmental substances. But D-negative persons can produce IgG anti-D antibodies [18]. Rh blood group was discovered by Landsteiner and Wiener in 1941 [19]. Rh antigens are largely immunogenic. D-negative persons produce anti-D if they encounter the D antigen through transfusion or pregnancy and causes hemolytic transfusion reaction of fetus and newborn. For this reason, the Rh status normally determined in blood donors, transfusion recipients and in mothers [20]. Recently studied that, ABO group not only for blood transfusion but also associated in various infectious disease transmission such as malaria, salivary gland tumors, colorectal cancer, carcinoma of stomach, thyroid disorder, ovarian tumors and small cell lung cancer [21]. Malaria is the most deadly parasitic infection in the worldwide. Malaria can transmit by blood transfusion, from mother to fetus and by using of infected needle. Malaria is generally transmitted by female Anopheles mosquito acting as a vector to disperse the genus of Plasmodium [22]. Plasmodium is transmitted to human by mosquito biting. This Plasmodium either enter into the RBCs or hepatocytes through the blood streams [23]. There are five species of Plasmodium known to cause malaria, such as; P. malariae, $P$. vivax, $P$. falciparum, P. ovale and P. knowlesi.P. vivax and P. falciparum species are mostly common in Pakistan [24].
Human Red Blood Cells (RBCs) or erythrocytes are the major sites of these parasites infection. The infected person suffers from the high fever, chills, nausea and anemia. Now is malaria known as the tropic disease [25]. Malaria transmission period for P.vivax peaking from June to September and again in April to June, when relapses on infections acquired the previous season are observed, while the transmission period for P.falciparum is between August and September in Pakistan [26]. The lifecycle of Plasmodium is very complex. Malaria caused in human by the transmission of plasmodium species through the mosquito female Anopheles. And these Plasmodium species transmits into the vertebrates [27]. Mostly female mosquito takes blood meals, because she needs supplementary blood meals to produce eggs. When a female mosquito bites it transmits sporozoites from its saliva into the human blood stream. Studies have shown that salivary duct of mosquito are blocked by these parasites, as results of which mosquito require more effort to achieve food [28]. Small amount of sporozoite engulf by macrophages and other by lymphatic system where they become destroyed. In the skin it is suppose that about $10 \%$ of the parasite remains which mature into infectious merozoites [29,30]. After entering of sporozoites into the liver cells they develop into the shizonts and these scizonts consists of merozoits. But in case of Pvivaxand P. ovale may exist in hypnozoite condition [31,32]. The travel of maturation and development of parasite from liver to RBCs are not clear. Later on a thousand of merozoites enclosed in merosomes which are budded off from hepatocytes which stay in pulmonary capillaries. Moderately it release meroizoites and degenerate. This all process takes 4872 hours. The maximum invasion of RBCs is closely packed cells and slow blood flow occurs in alveolar capillaries [33,34]. Within the erythrocyte merozoites develop into the trophozoites. During schizont stage are rapid division occurs and new merozoites are produce [35]. The merozoites change into the gametocytes (male and female gametes) within the bone marrow. The gametocytes are mostly present in the patient's blood, so mosquito takes it during blood meals. Gametocytes of P. falciparum take 7-15 days and 1-3 days in other species, to absorb in blood [36,37]. Gametocytes mature in gametes and fertilization occur in midgut of the mosquito and gametes change into the motile zygote known as ookinetes. Apoptosis occurs in $50 \%$ of the unknown reason. And the rest of ookinetes run away from the midgut through the periphery of the midgut membrane, and penetrates the liver and here it divides a few times to produce sporozoites. These sporozoites then go to salivary gland and during blood meals it inject into the blood of the host [38].

\section{Aim and Objectives}

The aim and objective of this study is to determine the prevalence of VDRL and MP and distribution of blood groups among males in swat (Figure 1). 


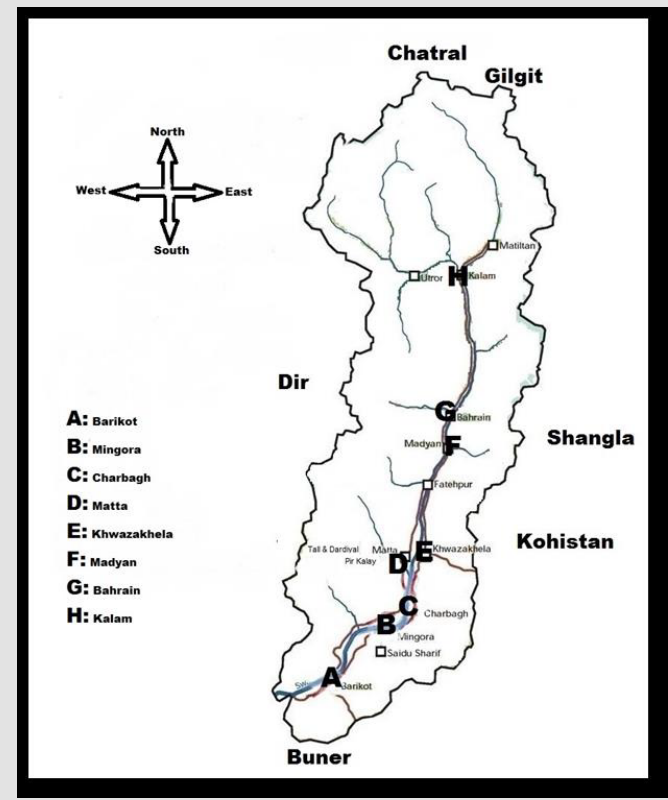

Figure 1: Study area district Swat, Khyber Pakhtunkhwa, Pakistan.

\section{Materials and Methods}

\section{Study Area}

Swat is the District of Khyber Pakhtunkhwa of Pakistan. This beautiful valley is located at $34^{\circ}-40$ to $35^{\circ}$ North latitude and 72 to 74-6 East longitude. Surrounded by Chatral (North), Buner and Malakand District (South) and Shangla District (East).

\section{Data Collection}

The study was conducted from July to December 2020 at University of Swat, Town Ship Kanju, Swat, Khyber Pakhtunkhwa, Pakistan. The blood was collected in blood bags from the all age of male students from different departments by the Informed Oral Consent. Total of 65 blood samples were collected in which, 24 blood samples were collected by the Al-Fajar Foundation team, Gulkada, Saidu Sharif Swat at November 2020 while 41 were collected by Frontier Foundation, Mingora, at July 2020. The blood samples were taken based on the body weight $(50<\mathrm{kg})$, it means that only those males had donated the blood whose had more than $50 \mathrm{~kg}$ weight and also based on the previous disease.

\section{Data Analysis}

The data was collected through the informed oral consent and then analyzed to determine the prevalence of VDRL and MP tests results among males and also determined the distribution of blood groups. So it was recorded that there were simple percentage of blood groups and non-reactive VDRL and MP among males.

\section{Results}

A total of 65 blood donors were VDRL and MP non-reactive (Table 1) and out of 65 blood donors, 14 (21.5\%) were $0+, 21$ (32.3\%) were $\mathrm{A}+, 21(32.3 \%)$ were $\mathrm{B}+, 2$ (3.07\%) were B-, 1 (1.53\%) were $\mathrm{AB}$ - and $6(9.23 \%)$ were $\mathrm{AB}+$ blood groups were determined and there $\mathrm{O}$ - and $\mathrm{A}$ - blood groups were not determined (Table 2). There were $0 \%$ prevalence of VDRL and MP negative among males, all of $100 \%$ negative (Figure 2).

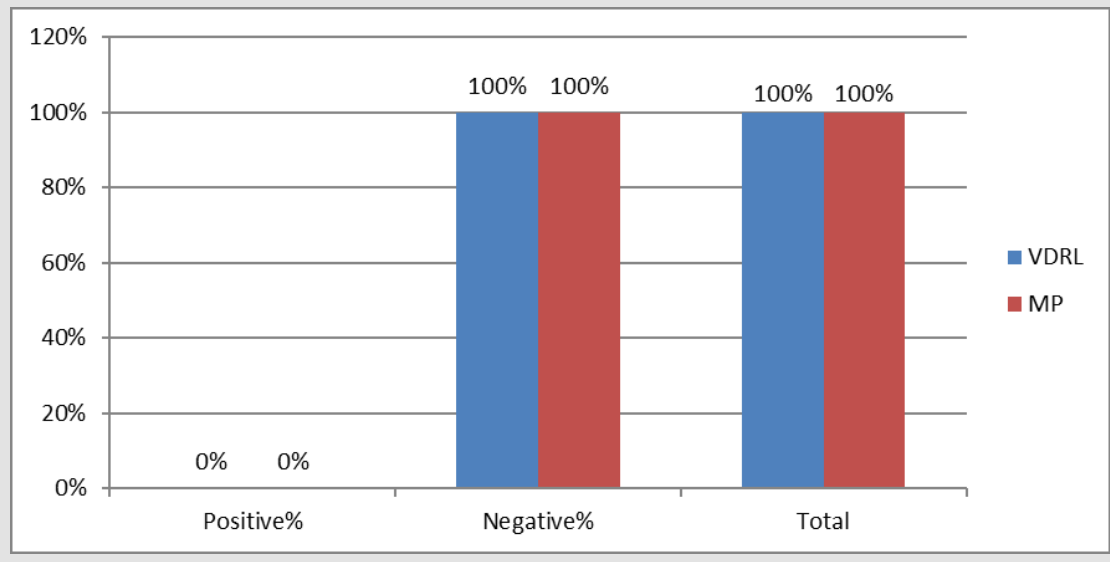

Figure 2: Prevalence of VDRL and MP among Males.

Table 1: Prevalence of VDRL and MP among Males.

\begin{tabular}{|c|c|c|c|c|}
\hline Parameters & Positive & Positive $\%$ & Negative & Negative $\%$ \\
\hline VDRL & 0 & 0 & 65 & $100 \%$ \\
\hline MP & 0 & 0 & 65 & $100 \%$ \\
\hline
\end{tabular}


Table 2: Prevalence of Blood Grouping among Males.

\begin{tabular}{|c|c|c|c|c|c|c|c|c|c|}
\hline \multicolumn{10}{|c|}{ Blood Grouping } \\
\hline Blood Groups & $\mathrm{O}+$ & $\mathrm{O}-$ & $\mathrm{A}+$ & $\mathrm{A}-$ & $\mathrm{B}+$ & $\mathrm{B}-$ & $\mathrm{AB}+$ & $\mathrm{AB}-$ & Total \\
\hline Frequencies & 14 & 0 & 21 & 0 & 21 & 2 & 6 & 1 & 65 \\
\hline
\end{tabular}

\section{Prevalence of Blood Grouping among Males}

Out of 65 blood donors, 14 (21.5\%) were 0+, 21 (32.3\%) were $A+, 21(32.3 \%)$ were $B+, 2$ (3.07\%) were $B-, 1(1.53 \%)$ were $A B$ - and $6(9.23 \%)$ were $A B+$ blood groups were determined and there 0 - and A- blood groups were not determined. The percentage of blood groups among males; $(21.5 \%)$ were $0+,(32.3 \%)$ were $\mathrm{A}+,(32.3 \%)$ were $\mathrm{B}+,(3.07 \%)$ were $\mathrm{B}-,(1.53 \%)$ were $\mathrm{AB}$ - and $(9.23 \%)$ were $\mathrm{AB}+$ blood groups were determined and there $\mathrm{O}$ - and $\mathrm{A}$ - were $0 \%$ (Figure 3).

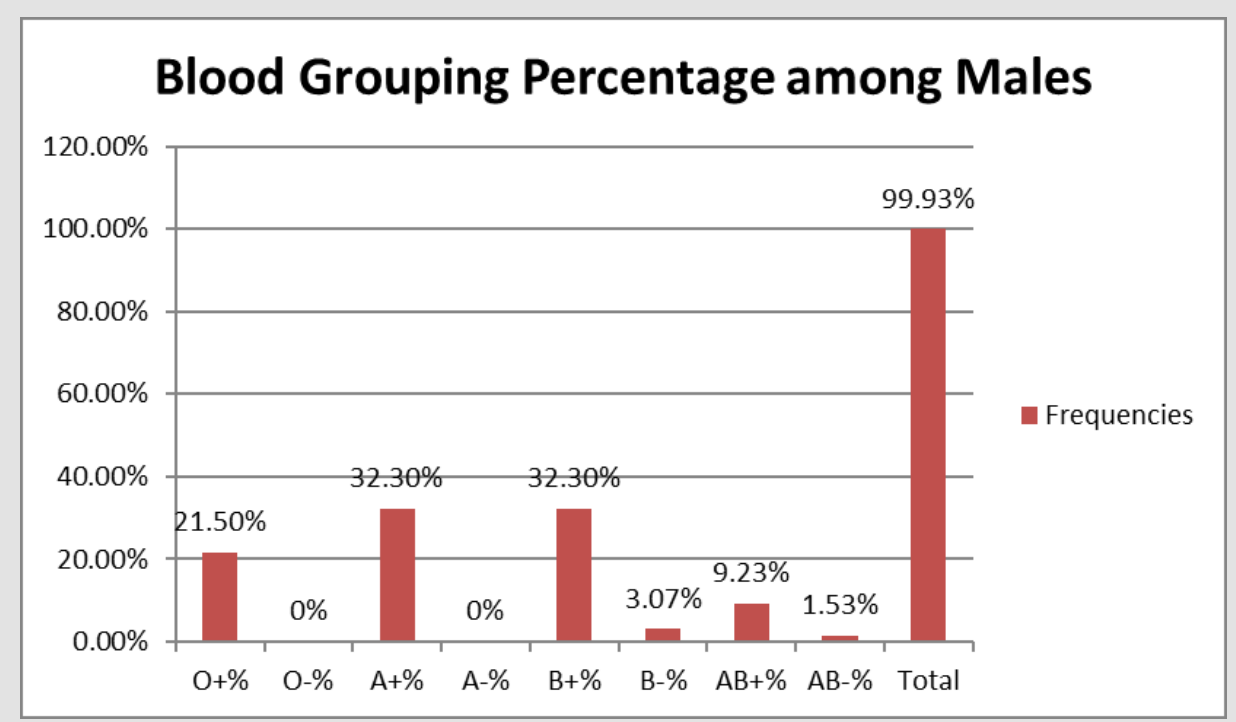

Figure 3: Percentage of Total Blood Groups among Males.

\section{ABO Blood Groups among Males}

The ABO blood grouping had different frequencies such as; 21 (32.30\%) were A blood group, 23 (35.38\%) were B blood group,
7 (10.76\%) were AB blood group and 14 (21.53\%) were 0 blood group (Table 3). There were $32.30 \%$ A blood group, $35.38 \% \mathrm{~B}$ blood group, $10.76 \%$ AB blood group and $21.53 \%$ O blood group among males (Figure 4).

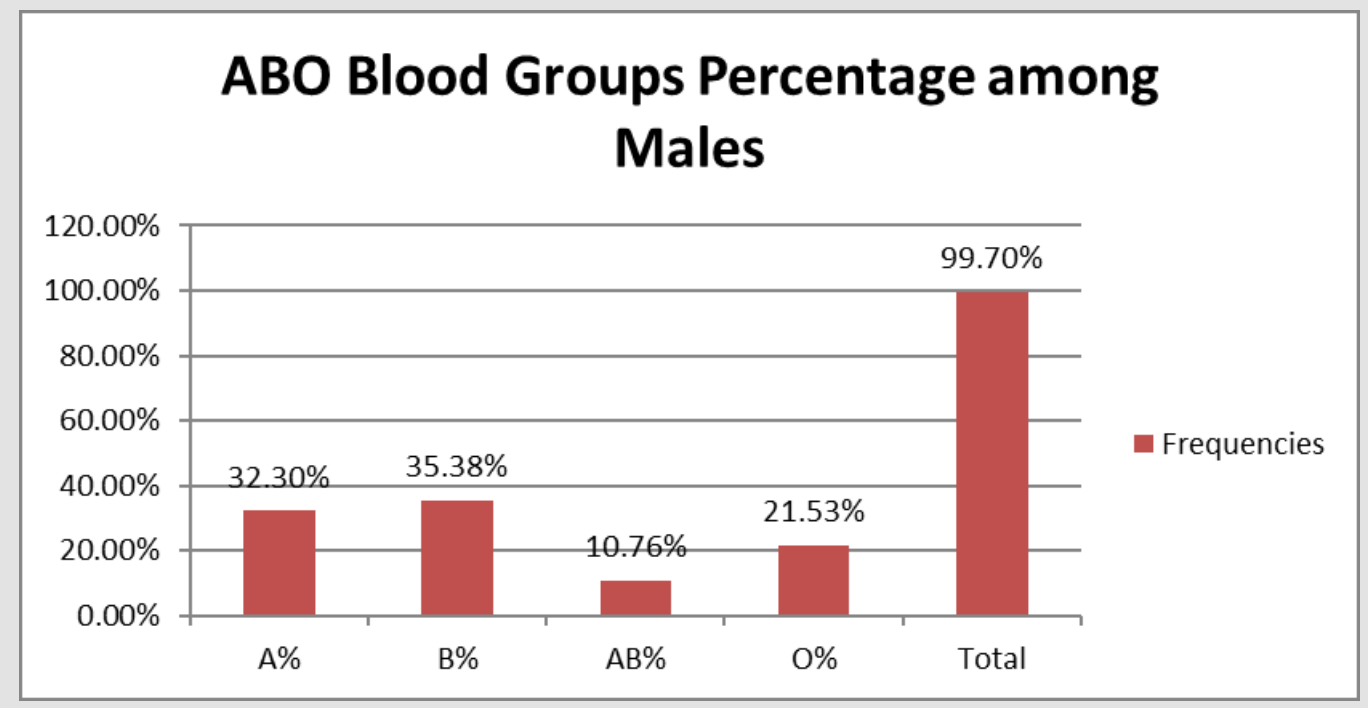

Figure 4: ABO Blood Groups Percentage among Males. 
Table 3: Distribution of ABO Blood Groups among Males.

\begin{tabular}{|c|c|c|c|c|c|c|c|c|c|}
\hline \multicolumn{10}{|c|}{ ABO Blood Groups } \\
\hline ABO Blood Groups & $\mathrm{A}$ & $\mathrm{A} \%$ & $\mathrm{~B}$ & $\mathrm{~B} \%$ & $\mathrm{AB}$ & $\mathrm{AB} \%$ & 0 & $0 \%$ & Total \\
\hline Frequencies & 21 & $32.30 \%$ & 23 & $35.38 \%$ & 7 & $10.76 \%$ & 14 & $21.53 \%$ & 65 \\
\hline
\end{tabular}

\section{Discussion}

In our study a total of 65 blood donors, 14 (21.5\%) were 0+, $21(32.3 \%)$ were $\mathrm{A}+, 21$ (32.3\%) were $\mathrm{B}+, 2$ (3.07\%) were $\mathrm{B}-, 1$ $(1.53 \%)$ were $A B-$ and $6(9.23 \%)$ were $A B+$ blood groups were determined and there 0 - and A- blood groups were not determined among males, and no reactive tests of VDRL and MP. The study was reported by Garg et al. (2014) at Tertiary Care Teaching Hospital of Kumaon Region of Uttarakhand in India, there was the frequency of A- $(1.72 \%)$ and $0-(1.55 \%)$ whereas in our study A- and 0 - were not found. Another study was reported by [39] on 429 female in District Peshawar, there was the frequency of $0-(27 \%)$ is greater than that of our population. The study was reported by Umer Khan et al. (2014) on 3000 male and female blood donors in Lahore, there was the frequency of blood group B (37.8\%) and 0 (28.8\%) greater than that of our population. The study was reported by [40] in Pakistan. A total of 707 PCR-positive samples in which; 128 (18\%) were P. falciparum, 536 (76\%) were P. vivax and 43 (6\%) were mixed P. falciparum and P. vivax. 94 microscopy positive samples were PCRnegative. In our study all of the malaria non-reactive cases were there. The study was reported by [41] in Pakistan. A total of 6119 suspected malaria cases in which 2346 were malaria positive cases on blood smear slides. In our study a total of 65 blood donors were malaria non-reactive. The study was reported by Peterman and Kidd (2020) in United State.

They worked on trends in death due to syphilis, during 19682015, 6498 deaths were caused, in which 4149 were males and 2349 were females. In the current study of the total 65 blood donors are VDRL non-reactive. Another study was reported by [42] at North India. A total of 28920 serum samples were collected in 6 years for VDRL testing. Out of 28920serum samples, 972 were reactive and 1722 were submitted for TPPA testing in which 374 were positive. In our study no reactive cases of VDRL were there. A study was reported by [43-46] in Karachi, Pakistan. They studied on 800 pregnant women. The prevalence of syphilis among women in Ibrahim Hyderi was $1.5 \%$ higher than in other sites $0.5 \%$. In our study there were no VDRL reactive cases among the males in swat.

\section{Conclusion}

This study concludes that there is no prevalence of VDRL and MP among male blood donors. All of 65 blood samples are VDRL and MP negative. And out of 65 male blood donors 14 (21.53\%) were $0+, 21(32.3 \%)$ were $A+, 21$ (32.3\%) were $B+, 2$ (3.0\%) were $B-, 1(1.5 \%)$ were $A B-$ and $6(9.2 \%)$ were $A B+$ whereas $A-$ and $0-$ blood groups were not found. So, it concludes that the blood groups
$\mathrm{A}$ - and $\mathrm{O}$ - are very rare in the Swat and $\mathrm{A}+$ and $\mathrm{B}+$ blood groups has very high frequency as compare to previous studies, it shows that the $\mathrm{A}+$ and $\mathrm{B}+$ blood group are very commonest blood groups in the District Swat.

\section{Acknowledgement}

I am very thankful to the Al-Fajar Foundation and Frontier Foundation for giving a data and a bid thank to my supervisor and co-supervisor for guiding me in the research work.

\section{References}

1. Nayak S, Acharjya B (2012) VDRL test and its Interpretation. Indian Journal of Dermatology 57(1): 3-8.

2. Chapel TA, Brown WJ, Jeffres C, Stewart JA (1977) How reliable is the morphological diagnosis of penile ulceration. Sex Transmission Disease 4(4): 150-152.

3. Shefer T, Strebel A, Wilson T, Shabalala N, Simbayi L, et al. (2002) The social construction of sexually transmitted infections (STIs) in South African communities. Qualitative Health Research 12(10): 1373-1390.

4. Wasserheit JN (1992) Epidemiologic synergy: Interrelationships between human immunodeficiency virus infection and other sexually transmitted diseases. Sexually Transmitted Diseases 19(2): 61-77.

5. French P (2011) Syphilis: Clinical Features, Diagnosis and Management. ABC of Sexually Transmitted Infections 192.

6. Allain JP, Stramer SL, Carneiro Proietti A, Martins M, Lopes da Silva S (2009) Transfusion-transmitted infectious disease. Biologicals 37(2): 71-77.

7. Gomez GB, Kamb ML, Newman LM, Mark J, Broutet N, et al. (2013) Untreated maternal syphilis and adverse outcomes of pregnancy. Bulletin World Health Organization 91(3): 217-226.

8. Lawn JE, Blencowe H, Waiswa P, Amouzou A, Mathers C (2016) Stillbirths: rates, risk factors, and acceleration towards 2030. Lancet 387(10018): 587-603.

9. Darville T (1999) Syphilis, Pediatrics in Review 20(5): 160-164.

10. Kahn JG, Jiwani A, Gomez GB, Hawkes SJ, Chesson HW, et al. (2014) The cost and cost-effectiveness of scaling up screening and treatment of syphilis in pregnancy: a model. PLoS One 9(1).

11. Owusu Edusei K, Tao G, Gift TL, Wang A, Wang L, et al. (2014) Costeffectiveness of integrated routine offering of prenatal HIV and syphilis screening in China. Sexually Transmitted Diseases 41(2): 103-110.

12. Li C, Xiao X, Yin H (2012) Prevalence and prevalence trend of transfusion transmissible infections among blood donors at four Chinese regional blood centers between 2000 and 2010. Journal of Translational Medicine 10: 176 .

13. Agarwal N (2012) Response rate of blood donors in the Uttarakhand region of India after notification of reactive test results on their blood samples. Journal of Blood Transfusion 5: 1-3.

14. Das S, Kumar MLH (2012) Association of blood group types to hepatitis $\mathrm{B}$ and hepatitis $\mathrm{C}$ virus infection among blood donors: a five year institutional based study. International Journal of Research in Medical Sciences 2(1): 191-195. 
15. Owen R (2000) Karl Landsteiner and the first human marker locus. Journal of Genetics 155(3): 995-998.

16. Jolly JG (2000) Medicolegal significance of human blood groups. Journal of Indian Medical Association 98(6): 340-341.

17. Harmening MD, Firestone D (2005) Modern Blood Banking and Transfusion Practices. Journal of Philadelphia 5: 108-132.

18. Talaro, Kathleen P (2005) Foundation of microbiology. In: Ka th le e $n$ Park Talaro, Arthur Talaro (Eds.)., International Standard Book Number ( $5^{\text {th }}$ Edn.)., McGraw-Hill, USA, pp. 510-511.

19. Rahman M, Lodhi Y (2004) Frequencies of ABO and Rhesus blood groups in blood donors in Punjab. Pakistan Journal of Medical Science 20(4): 315-318.

20. Bethesda DL (2005) The Rh blood group. National Center for Biotechnology Information, p. 1-6.

21. Woo SM, Joo J, Lee WJ, Park SJ, Han SS, et al. (2013) Risk of pancreatic cancer in relation to $\mathrm{ABO}$ blood group and hepatitis $\mathrm{C}$ virus infection in Korea. Journal of Korea Medical Science 28(2): 247-251.

22. Goering Richard V, Cerdic A, Mims Dockrell H, Zukerman M, Peter L Chiodini Roitt I (2013) Mims Medical Microbiology, with Student Consult Online Access. In: Richard Goering Hazel Dockrell Mark Zuckerman Peter Chiodini (Eds.)., Elsevier Health Sciences, Netherlands.

23. Liveson W, Jawetz E (2010) Mycobecteria. Medical Microbiology and Immunology 5: 157.

24. Collins WE (2012) Plasmodium knowlesi : a malaria parasite of monkeys and humans. Annual review of entomology 57: 107-121.

25. Hulden L, Mc Kitrick R, Hulden L (2014) Average household size and the eradication of malaria. Journal of the Royal Statistical Society: Series A 177(3): 725-742.

26. Bouma MJ, Dye C, Van der Kaay HJ (1996) Falciparum malaria and climate change in the northwest frontier province of Pakistan. Am J Trop Med Hyg 55(2): 131-137.

27. Greenwood M, Fidock A, Kyle E, Kappe S, Alonso L, et al. (2008) Malaria: progress, perils, and prospects for eradication. Journal of Clinical Investigation 118(4): 1266-1276.

28. Cogswell B (1992) The hypnozoite and relapse in primate malaria. Clinical Microbiology Review 5(1): 26-35.

29. Tanomsing N, Imwong M, Pukritayakamee S, Chotivanich K, Looareesuwan S, et al. (2007) Genetic analysis of the dihydrofolate reeducates- thymidylate synathase gene from geographically diverse isolates of Plasmodium malariae. Antimicrobial agents and chemotherapy 51(10): 3523-3530.

30. Sturm A, Amino R, Van de Sand C, Regen T, Retzlaff S, et al. (2006) Manipulation of host hepatocytes by the malaria parasites for delivery into liver sinusoids. Journal of Science 313(5791): 1287-1290.

31. Leitgeb M, Blomqvist K, Cho Ngwa F, Samje M, Nde P, et al. (2011) Loe anticoagulation heprin disrupts Plasmodium falciparum rosettes in fresh clinical isolates. The American Journal of tropical medicine and hygiene 84(3): 390-396.

\section{ISSN: 2574-1241}

DOI: 10.26717/BJSTR.2021.35.005665

Muzafar Shah. Biomed J Sci \& Tech Res

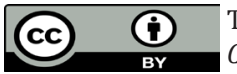

This work is licensed under Creative Commons Attribution 4.0 License

Submission Link: https://biomedres.us/submit-manuscript.php
32. Tamez A, Liu H, Fernandez Pol S, Haldar K, Wickrema A (2009) Stagespecific susceptibility of human erythroblast to Plasmodium falciparum malaria infection. Journal of Blood 114(17): 3652-3655.

33. Smalley ME, Sinden RE (1977) Plasmodium falciparum gametocytes: their longevity and infectivity. Parasitology 74(1): 1-8.

34. Field John W, Perey G (1956) A morphological study of the Erythrocytic Parasite. The Microscopic Diagnosis of Human Malaria 24.

35. Al Olayan M, Williams T, Hurd H (2002) Apoptosis in the malaria protozoan, Plasmodium berghei: a possible mechanism for limiting intensity of infection in the mosquito. International Journal for Parasitology 32(9): 1133-1143.

36. Hurd H, Grant M, Arambage C (2006) Apoptosis-like death as a feature of malaria infection in mosquitoes. Parasitology 132: 33-47.

37. Sologub L, Kuehn M, Kern S, Przyborski J, Schillig R, et al. (2011) Malaria proteases mediate inside-out egress of gametocytes from red blood cells following parasite transmission to the mosquito. Cellular Microbiology 13(6): 897-912.

38. Hopwood A, Ahmad M, Polwart A, Williams T, Hurd H (2001) Malariainduced apoptosis in mosquito ovaries. Journal of Experimental Biology 204(16): 2773-2780

39. Nazli R, Haider J, Khan MA, Akhtar T, Aslam H (2015) Frequency of $\mathrm{ABO}$ blood groups and RhD factor in the female population of District Peshawar. Pakistan Journal of Medical Sciences 31(4): 984-986.

40. Khattak AA, Venkatesan M, Nadeem MF, Satti HS, Yaqoob A, et al. (2013) Prevalence and distribution of human Plasmodium infection in Pakistan. Malaria Journal 12: 297.

41. Yasinzai MI, Kakarsulemankhel JK (2013) Prevalence of human malaria infection in Pakistan areas bordering with Iran. Journal of the Pakistan Medical Association 63(3): 313-316.

42. Sethi S, Mewara A, Hallur V, Prasad A, Sharma K, et al. (2015) Rising trends of syphilis in a tertiary care center in North India. Indian Journal of Sex Transmission Diseases AIDS 36(2): 140-143.

43. Shah SA, Kristensen S, Memon MA, Usman G, Ghazi A, et al. (2011) Prevalence of syphilis among antenatal clinic attendees in Karachi: Imperative to begin universal screening in Pakistan. Journal of Pakistan Medical Association 61(10): 993-997.

44. Garg P, Upadhyay S, Chufal SS, Hasan Y, Tayal I (2014) Prevalance of ABO and Rhesus Blood Groups in Blood Donors: A Study from a Tertiary Care Teaching Hospital of Kumaon Region of Uttarakhand. Journal of Clinical and Diagnostic Research 8(12): 16-19.

45. Khan MU, Bashir MW, Rehman R, Kiani RA (2014) Frequency of ABO and Rh (D) Blood Groups among Blood Donors in Lahore, Pakistan. International Journal of Advanced Biological and Biomedical Research 2(3): 597-600.

46. Peterman TA, Kidd SE (2019) Trends in Deaths due to Syphilis, United States, 1968-2015. Sexually Transmitted Diseases 46(1): 37-40.

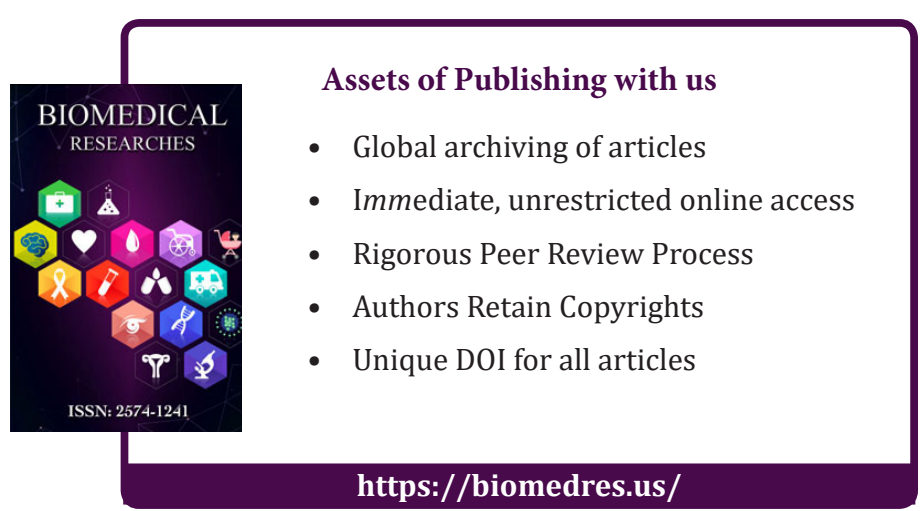

